\title{
SOBRE A FUNÇÃO DAS REPRESENTAÇÕES CONCEITUAIS SIMBÓLICAS NA GRAMÁTICA DO DESIGN VISUAL: ENCAIXAMENTO OU SUBJACÊNCIA?
}

\author{
Bernardete Biasi-Rodrigues* \\ Kennedy Cabral Nobre***
}

Resumo: Nosso objetivo neste trabalho é discutir a função das categorias gramaticais atributo simbólico e portador na Gramática do Design Visual (KRESS e van LEEUWEN, 2006 [1996]). Para os autores, estes constituintes, pertencentes à metafunção ideacional, poderiam estar presentes ou não em estruturas conceituais simbólicas, conferindo a um participante um valor que o caracterizaria elou o conceituaria. Advogamos aqui que, decorrente dessa função, os atributos simbólicos e os portadores são responsáveis pela realização de inferências por parte dos leitores de imagens e, portanto, estão sempre presentes em quaisquer representações visuais. Em virtude disso, entendemos que as representações conceituais simbólicas não estão no mesmo nível de autonomia que as representações narrativas e conceituais classificatórias e analíticas, e sim num nível de subjacência.

Palavras-chave: multimodalidade; textos visuais; estruturas representacionais; atributos simbólicos.

\section{INTRODUÇÃO}

O mundo ocidental, durante muito tempo, deu preferência a um tipo de produção discursiva monomodal, ou seja, priorizando a linguagem verbal, escrita ou falada, em detrimento a outras formas de interação tais como imagem ou música, por exemplo (KRESS; VAN LEEUWEN, 2001). Na verdade, num sentido amplo, nunca poderíamos ter uma produção de linguagem exclusivamente monomodal, em virtude

\footnotetext{
* Professora do Departamento de Letras Vernáculas e do Programa de Pós-Graduação em Linguística da UFC. Coordenadora do grupo de pesquisa TRADICE (www.tradice.ufc.br). E-mail: bernardete.biasi@gmail.com.

** Mestre em Linguística pela Universidade Federal do Ceará. E-mail: cabralnobre@yahoo.com.br.
} 
de aspectos melódicos e/ou prosódicos em relação à fala, e de características tipográficas e/ou caligráficas em relação à escrita, mas não se pode desconsiderar a afirmação dos autores no que concerne à priorização da linguagem verbal na cultura ocidental. Só para termos ideia, a Análise da Conversação agrupa sob o rótulo de material paraverbal "todas as unidades que acompanham as unidades propriamente linguísticas e que são transmitidas pelo canal auditivo: entonações, pausas, intensidade articulatória, elocução, particularidades da pronúncia, características da voz." (KERBRAT-ORECCIONI, 2006, p. 36 - grifos nossos), de modo que todos esses fatores isolados são considerados por essa vertente como não pertencentes ao material propriamente linguistico.

Entretanto, segundo Kress e van Leeuwen (2001), ao longo do século $\mathrm{XX}$, outros recursos semióticos paulatinamente passaram a conviver com a linguagem verbal e hoje é bastante comum, especialmente em gêneros textuais mais plásticos (como o anúncio) ou emergentes (como os gêneros da web), a produção de discursos multimodais, ou seja, de práticas comunicativas para as quais convergem mais de uma forma de linguagem, resultando em um código integrado no qual nem sempre há, como observou Barthes (1976), uma dependência ou complementaridade de uma semiose em relação a outra. Pelo contrário, como bem observam Kress e van Leeuwen (2006 [1996], p. 18), focalizando a relação entre texto verbal e pictórico, "o componente visual de um texto é uma mensagem organizada e estruturada independentemente, conectada ao texto verbal, mas de nenhuma forma dependente dele e vice versa" ${ }^{1}$. Esse movimento em direção a uma produção de discurso multimodal pode ser explicado tanto pelo surgimento de novas tecnologias (rádio, TV, e, mais recentemente, a internet), quanto pelo progressivo apagamento entre fronteiras sociais (FAIRCLOUGH, 2003; CHOULIARAKI e FAIRCLOUGH, 1999) que possibilitou essa e outras formas de hibridização discursiva quando antes a rigidez das convenções, altamente institucionalizadas, não a permitia.

Saussure já previa a relação entre o sistema de signos linguísticos com outros sistemas semióticos na seguinte afirmação:

\footnotetext{
${ }^{1}$ Nossa tradução de "the visual component of a text is an independently organized and structured message, connected with the verbal text, but in no way dependent on it - and similarly the other way around."
}

BIASI-RODRIGUES; NOBRE - Sobre a função das representações conceituais... 
Pode-se, então, conceber uma ciência que estude a vida dos signos no seio da vida social; ela constituiria uma parte da Psicologia geral; chamá-la-emos de Semiologia (do grego sèmeîon, "signo"). Ela nos ensinará em que consistem os signos, que leis os regem. [...]. A linguística não é senão uma parte dessa ciência geral; as leis que a Semiologia descobrir serão aplicáveis à Linguística e esta se achará dessarte vinculada a um domínio bem definido no conjunto dos fatos humanos. (SAUSSURE, 1975 [1916], p. 24, grifos originais).

Concretizando em parte o prognóstico do linguista genebrino, ocorre atualmente a incorporação do estudo de outras semioses principalmente imagens - na área da linguística, ocasionada, especialmente, pela mudança da perspectiva epistemológica que vem ocorrendo nessa ciência, do sistema imanente para a abordagem da língua em uso (abrangendo os estudos de gêneros textuais/discursivos).

No que se refere à produção de imagens, Kress e van Leeuven (2006 [1996]) advogam que as estruturas visuais se assemelham às linguísticas, pois elas expressam interpretações particulares da experiência dos produtores e são também formas de interação social, de modo que a crescente proliferação de práticas comunicativas por meio de textos não verbais (ou, mais comumente, pela mescla entre o verbal e o não verbal) possibilitada pelos mais diversos meios, requer um letramento visual. Nesse contexto, é produzida a Gramática do Design Visual (doravante GDV), que tem por intuito descrever de modo explícito e sistemático os significados das regularidades encontradas em imagens produzidas na cultura ocidental, tornando-se um instrumento de apoio para os estudos linguísticos quando os objetos de análise forem textos/gêneros multimodais constituídos, no mínimo, pelos códigos semióticos verbal e visual.

A GDV, inspirada nos padrões da gramática de Halliday (1994 [1985]), possui um amplo repertório de categorias de análise que reforçam a descrição e interpretação das mais diversas composições visuais, de esquemas teóricos a imagens abstratas. Dentre essas categorias encontram-se os portadores e os atributos simbólicos, que conferem valores a participantes num processo conceitual simbólico, indicando o que o participante significa ou é. Entretanto, a partir da análise de alguns gêneros visuais e/ou multimodais, tais como anúncios, 
capas de revistas, etc., verificamos que esses elementos são também responsáveis pelas inferências que os leitores fazem, colocando-os num nível mais elevado que o imputado pelos autores. Nosso propósito neste artigo é levantar a discussão em torno das funções da estrutura conceitual simbólica em algumas realizações empíricas, e ampliar a abrangência dessas funções.

\section{SOBRE A GRAMÁTICA DO DESIGN VISUAL}

Diferentemente de outras áreas que também abordam imagens como objeto de estudo, tais como a história da arte, a psicologia da composição ou a estética, o intuito de Kress e van Leeuwen (2006), ao empreender a elaboração de sua gramática, foi verificar os significados das regularidades encontradas em estruturas visuais produzidas na cultura ocidental, abordando-as de um modo sistemático.

Tributários da Linguística Sistêmico Funcional (doravante LSF), os autores construíram um sistema de estruturação visual em que se encontram três significados simultâneos: um ideacional, uma vez que é possível realizar em imagens modos de representação do mundo; um interpessoal, pois se estabelece uma interação entre a imagem e seus expectadores, na qual papéis sociais são também estabelecidos; e um textual, visto que as formas de organização de uma imagem contribuem para a construção de seus significados. Para cada uma dessas metafunções, os autores estabelecem categorias e subcategorias de análise (ver quadro 1), algumas das quais, de acordo com os pressupostos da LSF, não podem coexistir em um mesmo elemento, isto é, a escolha de determinada categoria anularia a possibilidade de atualização das demais.

\begin{tabular}{|l|l|}
\hline Metafunção ideacional & - Estrutura narrativa \\
& - Estrutura conceitual \\
\hline Metafunção interpessoal & - Contato \\
& - Distância social \\
& - Atitude \\
& - Poder \\
\hline Metafunção textual & - Valor da informação \\
& - Saliência \\
& - Enquadre \\
\hline
\end{tabular}

Figura 1 - Categorias centrais das metafunções da GDV.

BIASI-RODRIGUES; NOBRE - Sobre a função das representações conceituais... 
Muitas categorias da GDV, vale ressaltar, apresentam-se senão correspondentes, pelo menos análogas, às da LFS, como é o caso de algumas das estruturas representacionais/metafunção ideacional, por exemplo, que têm a mesma nomenclatura (ator, meta, fenômeno, atributo possessivo, comportante, etc.), ou apresentam certa equivalência (como os vetores que se equiparam aos processos). Como o foco desse artigo está especificamente na discussão em torno dos processos conceituais simbólicos, categoria pertencente à metafunção ideacional, não cabe aqui resenharmos o cerne da estrutura da $\mathrm{GDV}^{2}$, por isso nos limitamos a sintetizar a estrutura representacional.

Antes, porém, é importante explicar que Kress e van Leeuwen (2006 [1996]) distinguem dois tipos de participantes que interagem por meio de imagens, os participantes representados (seres, animados ou inanimados, presentes nos textos visuais) e participantes interativos (o produtor e o receptor). Esses participantes podem interagir por meio de três modos de relação:

a) Entre participantes representados;

b) Entre participantes interativos;

c) Entre participantes interativos e representados.

A estrutura representacional, análoga à metafunção ideacional da LSF, diz respeito aos modos de representação do mundo que podem ser realizados a partir de estruturas visuais e cuida somente das diversas relações entre os participantes representados, sem considerar os participantes interativos. Consequentemente, os principais constituintes dessa metafunção são os participantes representados, que podem ser pessoas, objetos, lugares, formas geométricas e/ou abstratas.

De forma equivalente aos seis diferentes processos da metafunção ideacional postulados por Halliday (1994 [1985]), referentes à linguagem verbal ${ }^{3}$, Kress e van Leeuwen (2006 [1996]) apontam dois processos principais: as estruturas narrativas $\mathrm{e}$ as estruturas conceituais. Sua diferença básica repousaria no pressuposto que em estruturas narrativas uma ação estaria ocorrendo, ou seja, os

\footnotetext{
${ }^{2}$ Para a leitura, em português, do tratamento exaustivo dessas categorias, com farta exemplificação, sugerimos a leitura de Pinheiro e Magalhães (2006) e Knoll (2007).

${ }^{3}$ A saber, material, comportamental, mental, existencial, relacional e verbal.
} 
participantes estariam realizando alguma atividade, ao passo que em estruturas conceituais os participantes representados teriam um comportamento estático e, de certa maneira, descontextualizado. Além disso, haveria um constituinte nas estruturas narrativas não pertencente às conceituais, os vetores, indispensáveis, portanto para sua diferenciação. Conforme Kress e van Leeuwen (2006 [1996], p. 46), “o que na linguagem é realizado por palavras da categoria 'verbos de ação', é visualmente realizado por elementos que podem ser formalmente definidos como vetores" 4 . Os vetores, numa imagem, são linhas que podem estar representadas de forma expressa ou tácita, (neste último caso, pode-se perceber o vetor por meio de diferentes pistas que causam o efeito de movimento na imagem).

As estruturas narrativas dividem-se em acionais e reacionais. A estrutura básica de um processo de ação realiza-se a partir de um vetor que parte de um participante, o ator, e atinge outro, a meta. Entretanto, há várias possibilidades de representação, já que se tem a alternativa de escolher quais e quantos participantes serão efetivamente retratados. $\mathrm{Na}$ figura 2, a seguir, resumimos as principais possibilidades de representação.

As estruturas narrativas reacionais, por sua vez, têm como vetor a linha do olho que parte de um dos participantes, o reator, e dirige-se a outro, o fenômeno. Kress e van Leeuwen ([1996] 2006) seguem os mesmos padrões classificatórios utilizados nos processos de ação, de modo que podemos ter, numa determinada imagem, uma reação unidirecional transacional (reator - vetor - fenômeno); uma reação unidirecional não transacional (reator - vetor); e uma reação bidirecional transacional (reator - vetor - reator). Não se considera, todavia, um vetor saindo da linha do olho de uma imagem e atingindo um expectador, visto que, nesse caso, configurar-se-ia uma relação entre participante representado e interativo, escopo da estrutura interacional.

Vale ainda informar sobre a existência dos processos narrativos mentais e verbais, em que há, nas imagens, balões de pensamento e de fala, respectivamente, típicos de gêneros como histórias em quadrinhos,

\footnotetext{
${ }^{4}$ Nossa tradução de: "what in language is realized by words of the category 'action verbs' is visually realized by elements that can be formally defined as vetors".
}

BIASI-RODRIGUES; NOBRE - Sobre a função das representações conceituais... 
tirinhas e charges, mas não necessariamente restritos a essas formas de interação.

\begin{tabular}{|l|l|}
\hline $\begin{array}{l}\text { Relação entre participantes } \\
\text { representados }\end{array}$ & Denominação \\
\hline Ator - vetor - meta & Ação unidirecional transacional \\
\hline Ator - vetor & Ação unidirecional não transacional \\
\hline Interator $^{5}-$ vetor - interator & Ação bidirecional transacional \\
\hline Vetor - meta $_{\text {Ator }- \text { vetor }- \text { revezamento }}{ }^{6}-$ vetor \\
- meta & Evento \\
\hline
\end{tabular}

Figura 2 - Processos narrativos de ação da GDV.

Além das estruturas narrativas, os autores tratam das estruturas conceituais, que, desprovidas de vetores, apresentam-se de forma estabilizada e sem características acionais. Para Kress e van Leeuwen (2006 [1996]), há três processos distintos: os classificatórios, os analíticos e os simbólicos. Os classificatórios são aqueles em que um número indefinido de participantes seria subordinado a outro, o superordenado. Cabe apontar que, nesses casos, os participantes são mostrados de uma forma objetiva, geralmente simétrica e, principalmente, são julgados como membros de um grupo particular. Quanto aos processos analíticos, não expomos aqui sua variada subclassificação, apenas salientamos que seu critério repousa na relação parte-todo.

Por fim, têm-se os processos simbólicos, que se referem ao significado atribuído ou intrínseco a um participante qualquer. São subdivididos em dois tipos: os processos simbólicos atributivos que apresentam apenas um participante, o portador, que já teriam um conceito/significado intrínseco, cujo conhecimento seria prévio ao expectador da imagem e, portanto, teriam o caráter de signos; e os processos simbólicos sugestivos, que teriam, além do portador, elementos a partir dos quais se poderiam atribuir significados àquele constituinte, os atributos simbólicos.

\footnotetext{
${ }^{5}$ Ator que é meta de outro numa relação de reciprocidade.

${ }^{6}$ Quando, simultaneamente, a meta de um processo é ator de outro, sem relação de reciprocidade, Kress e van Leeuwen (2006 [1996]) denominam este participante de revezamento (relay).
} 
Em síntese, para os autores, todas as categorias da rede semântica das estruturas representacionais são consideradas equivalentes e autônomas. Defendemos, todavia, que as estruturas simbólicas não têm a mesma autonomia que as demais estruturas representacionais (narrativas acionais e reacionais, e conceituais classificatórias e sugestivas), no sentido de que, para haver a compreensão de uma imagem, é necessário ao expectador deter um conhecimento prévio a respeito dos significados simbólicos representados. Em outras palavras, as representações simbólicas estão inevitavelmente presentes numa composição visual ${ }^{7}$, assim como não é possível dissociar qualquer forma de comunicação (realizada em qualquer semiose) de conjuntos de crenças, valores e ideologias socialmente aceitos.

$\mathrm{Na}$ perspectiva dos autores essa equivalência e autonomia podem ser representadas como se verifica no esquema 3.

Como é possível perceber a partir do esquema, as estruturas representacionais são produzidas a partir de escolhas motivadas, assim como na linguagem verbal, por coações contextuais como gênero, registro e ideologia. Uma escolha de uma determinada categoria requer necessariamente o descarte das demais, conforme simbolizado pela utilização dos colchetes abertos na Figura 3. Em outras palavras, a escolha de uma estrutura representacional narrativa implica a exclusão de uma estrutura representacional conceitual; assim como a escolha de uma estrutura conceitual classificatória anularia a representação simultânea de uma estrutura conceitual analítica ou simbólica.

Entretanto, há problemas com essa afirmação, cabendo nesse ponto a discussão a respeito da unidade de análise da estrutura visual utilizada pelos autores. Enquanto na LSF a unidade de análise é a oração, isso não fica claro na GDV. Numa oração, a escolha de um processo material (considerando somente a metafunção ideacional) elimina a possibilidade de representação, nessa mesma oração, dos demais tipos de processo (comportamental, mental, existencial, relacional e verbal); contudo, pode-se afirmar sumariamente que um

\footnotetext{
${ }^{7}$ Não somente em textos visuais, entendemos que qualquer forma de representação simbólica (conjunto de crenças, valores, ideologias) encontra-se subjacentes e indissociáveis a qualquer manifestação discursiva.
}

BIASI-RODRIGUES; NOBRE - Sobre a função das representações conceituais... 
conjunto de orações possibilita a construção de um texto ${ }^{8}$ que, por sua vez, representa uma unidade de sentido, composto de várias orações que, não obstante, podem representar diferentes processos.

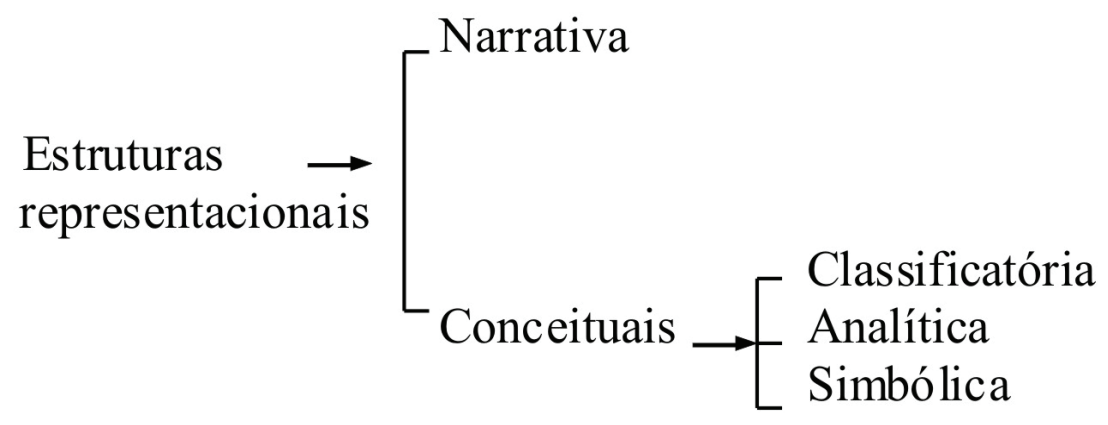

Figura 3 - Principais tipos de estruturas representacionais visuais (KRESS; VAN LEEUWEN, 2006, [1996], p. 59).

$\mathrm{Na}$ GDV observa-se que não fica claro se as imagens que são analisadas equivalem à oração ou ao texto. À medida que as categorias são enumeradas e ilustradas, percebemos uma inclinação dos autores em tratar as imagens de forma equivalente às orações - principalmente no que se refere ao sistema de representação ideacional. No entanto, é possível verificar numa única imagem a coexistência pacífica de diferentes formas de representação experiencial, de modo que é mais oportuno, em decorrência disso, equipararmos uma imagem à unidade que, em linguagem verbal, seria reconhecida como um texto. Convém nesse ponto lembrar que, para Bakhtin ([1959-1961] 2000), o termo texto poderia ser utilizado para identificar um conjunto coerente de signos não linguísticos. Segundo ele, "se tomarmos o texto no sentido amplo de conjunto coerente de signos, então também as ciências da arte (a musicologia, a teoria e a história das artes plásticas) se relacionam com textos" (p. 329).

Um outro problema que percebemos no tratamento de imagens na GDV é a inconstância na seleção dos exemplos no que se refere a uma imagem que por si só tenha autonomia ou que esteja atrelada a uma outra semiose, principalmente verbal. Por vezes, o material analisado é a íntegra de um gênero textual multimodal (como anúncios de natureza diversa) ou obras de arte como pinturas. Mas, por vezes observa-se que

\footnotetext{
${ }^{8}$ No entanto, não queremos dizer com isso que entendemos língua como uma estrutura modular "como a 'teoria da cebola', em que os diversos níveis ou camadas em que se faz a descrição linguística são vistos como superpostos ou acrescentados uns aos outros sucessivamente." (KOCH, 2008, p. 11-2).
} 
as imagens foram extraídas dos gêneros textuais de origem e analisadas isoladamente, como muitas ilustrações retiradas de textos científicos diversos (gráficos, esquemas e tabelas, por exemplo), de forma que a análise da imagem é realizada dissociada do texto verbal que a acompanha e/ou das variáveis relacionadas aos diferentes contextos de produção (suporte e mídia de veiculação da imagem e público ao qual se destina). Nesse caso, as imagens analisadas não têm autonomia para circulação e a sua identificação como unidades de significado fica relativamente comprometida.

Obviamente esses problemas são gerados devido à comparação da semiose visual com a linguística, ato bastante natural, visto que os critérios de análise originais - ou seja, derivados da LSF - são exclusivamente linguísticos. Conforme Kress e van Leeuwen (2006 [1996]), as estruturas visuais são comparáveis às linguísticas, pois distintos elementos combinam-se a fim de produzir uma unidade de significado; entretanto, consoante ressaltam os autores, nem sempre essas duas semioses são intercambiáveis: há mensagens realizadas na linguagem verbal que não poderiam ser produzidas em linguagem visual surtindo os mesmos efeitos, e vice-versa. A diferença está em que um texto realizado em linguagem verbal pode ser segmentado em diferentes unidades significativas (morfemas, sintagmas e orações), se levarmos em consideração o aspecto estritamente linguístico; mas também macroproposições (unidades retóricas, estágios, sequências, entre outras), se levarmos em consideração as diferentes estratégias de textualização. $\mathrm{O}$ mesmo, certamente, não se aplica à segmentação em estruturas visuais, pois os padrões de organização da linguagem visual são construídos a partir de convenções diferentes dos parâmetros que regem o sistema linguístico.

A negligência de tais considerações provoca problemas na análise de imagens. Vejamos o exemplo (1), que pode ser classificado, segundo o sistema representacional, como uma ação em que está representada somente a meta (no caso, o tronco da árvore) e o vetor, as linhas oblíquas brancas. Consoante os critérios da GDV, o exemplo (1) representaria um evento, pois "há somente um vetor e uma Meta. A Meta é o participante a quem o vetor é dirigido [...] Representações de ações que incluem somente a Meta nós chamaremos Eventos: algo está acontecendo a alguém, mas nós não podemos ver quem ou o quê faz isso 
acontecer" ${ }^{\prime 9}$ (KRESS; VAN LEEUWEN, 2006 [1996], p. 64, grifos originais).

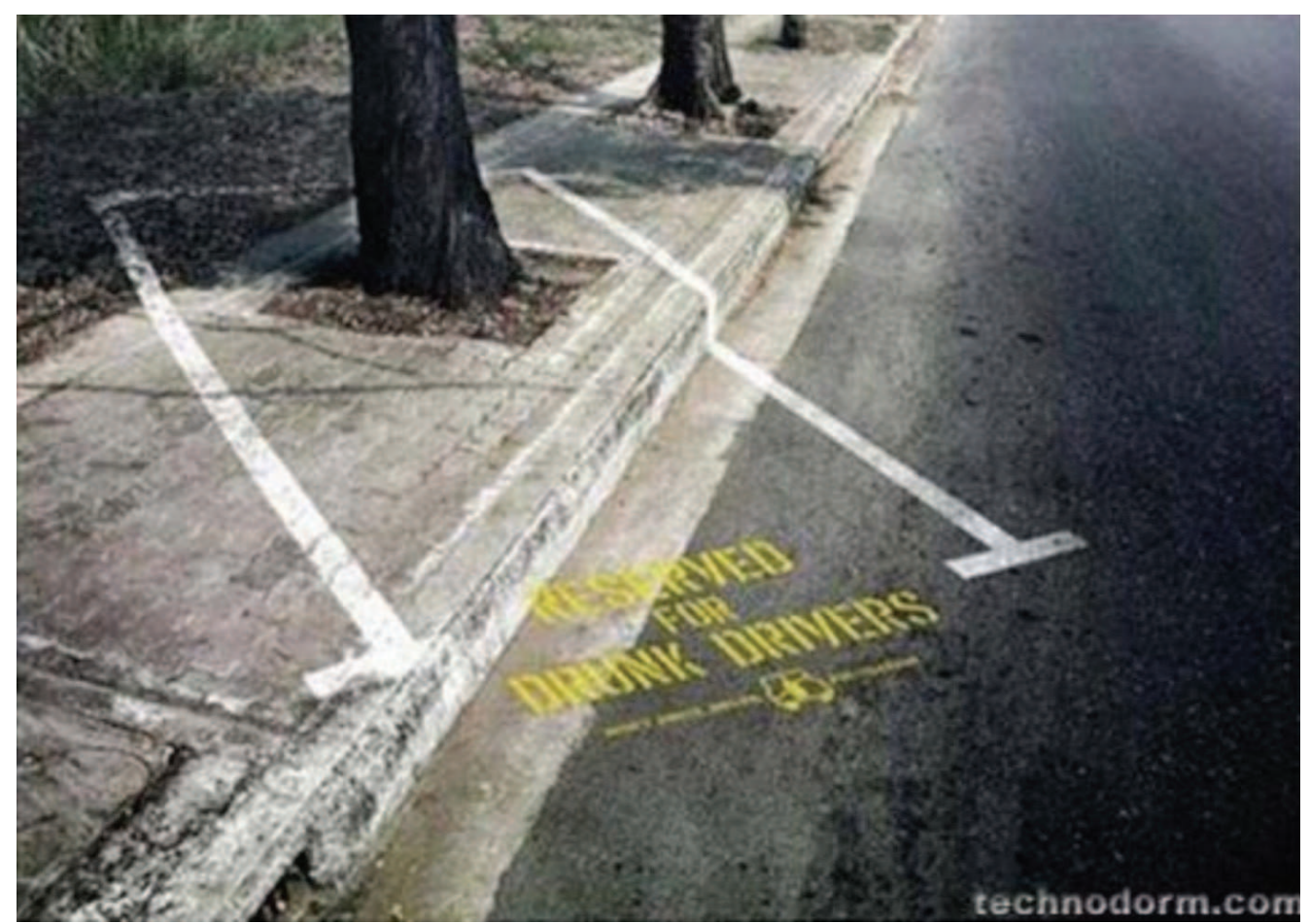

Podemos inferir, então, que um veículo automotor, não representado na imagem, irá colidir com o tronco da árvore, inferência ratificada pela leitura do texto verbal, no qual a oração "reservado a motoristas bêbados" $" 10$, possibilita a compreensão da ironia deste anúncio de teor pedagógico. Além disso, as linhas que demarcam o espaço de um carro são, simultaneamente, vetores e atributos simbólicos, pois representam um local reservado para estacionamento. Tal representação é discursiva, no sentido de que há uma convenção socialmente estabelecida no que diz respeito ao significado dessas linhas, em outras palavras, essas duas linhas brancas paralelas pintadas no chão, com razoável distância entre si, assumem o status de signo. Para Bakhtin/Voloshinov (2002 [1926], p. 36-7), “cada domínio possui seu próprio material ideológico e formula signos e símbolos que lhe são

\footnotetext{
${ }^{9}$ Nossa tradução de "There is only a vector and a Goal. The Goal is the participant at whom or which the vector is directed [...] Representations of actions which include only Goal we will call Events: something is happening to someone, but we cannot see who or what makes it happen".

${ }^{10}$ Nossa tradução de "Reserved for drunk drivers".
} 
específicos e que não são aplicáveis a outros domínios. O signo, então, é criado por uma função ideológica precisa e permanece inseparável dela." Nesse contexto, as linhas de demarcação estão inseridas num domínio institucional relativo às normas de tráfego e estacionamento de veículos.

Tal sobreposição de funções, todavia, é sumariamente prevista na GDV quando os autores falam em encaixamento. Afirmam os autores que, "na linguagem, sentenças podem ser simples (consistindo de somente uma oração/processo) ou complexas (contendo várias orações, cada qual com seus próprios processos, coordenadas ou subordinadas umas às outras). Imagens também podem ser simples ou complexas" "11 (KRESS e VAN LEEUWEN, 2006 [1996], p. 107). Em síntese, assim como na linguagem verbal há orações encaixadas (embedded), o mesmo fenômeno pode ocorrer na linguagem visual. Vejamos como isso se materializa numa imagem no exemplo (2).

Nesse pôster, onde se anuncia o filme Little miss Sunshine, percebe-se o encaixamento de duas representações principais entre as imagens localizadas antes e depois do título. Acima dele, há uma imagem conceitual composta por uma série de fotografias justapostas cuja integração se identifica como classificatória, pois há "pelo menos um conjunto de participantes que cumprirão o papel de Subordinados em relação a pelo menos outro participante, o Superordenado" (KRESS; VAN LEEUWEN, 2006 [1996], p. 79, grifos originais). No caso em amostra, as fotografias representam o elenco que interpreta as personagens centrais do longa-metragem. A disposição simétrica na composição dessas fotografias reforça a imagem como uma representação conceitual classificatória. Abaixo do título do filme, temos outra imagem que se encaixa à primeira e também contém duas representações narrativas encaixadas: há quatro participantes na função semântica de ator cuja meta é a Kombi, constituindo-se um processo de ação transacional; e, simultaneamente, a Kombi ${ }^{12}$ é ator cuja meta não está representada na imagem, constituindo-se, por sua vez, um processo de ação não transacional.

\footnotetext{
${ }^{11}$ Nossa tradução de "In language, sentences can be simple (consisting of only one clause/process) or complex (containing several clauses, each with own process, coordinated with or subordinated to each other). Pictures, too, can be simple or complex".

${ }^{12}$ A Kombi também pode ser interpretada como circunstância de modo por meio da qual os atores atingirão sua meta, esta última não representada na imagem.
}

BIASI-RODRIGUES; NOBRE - Sobre a função das representações conceituais... 
(2)

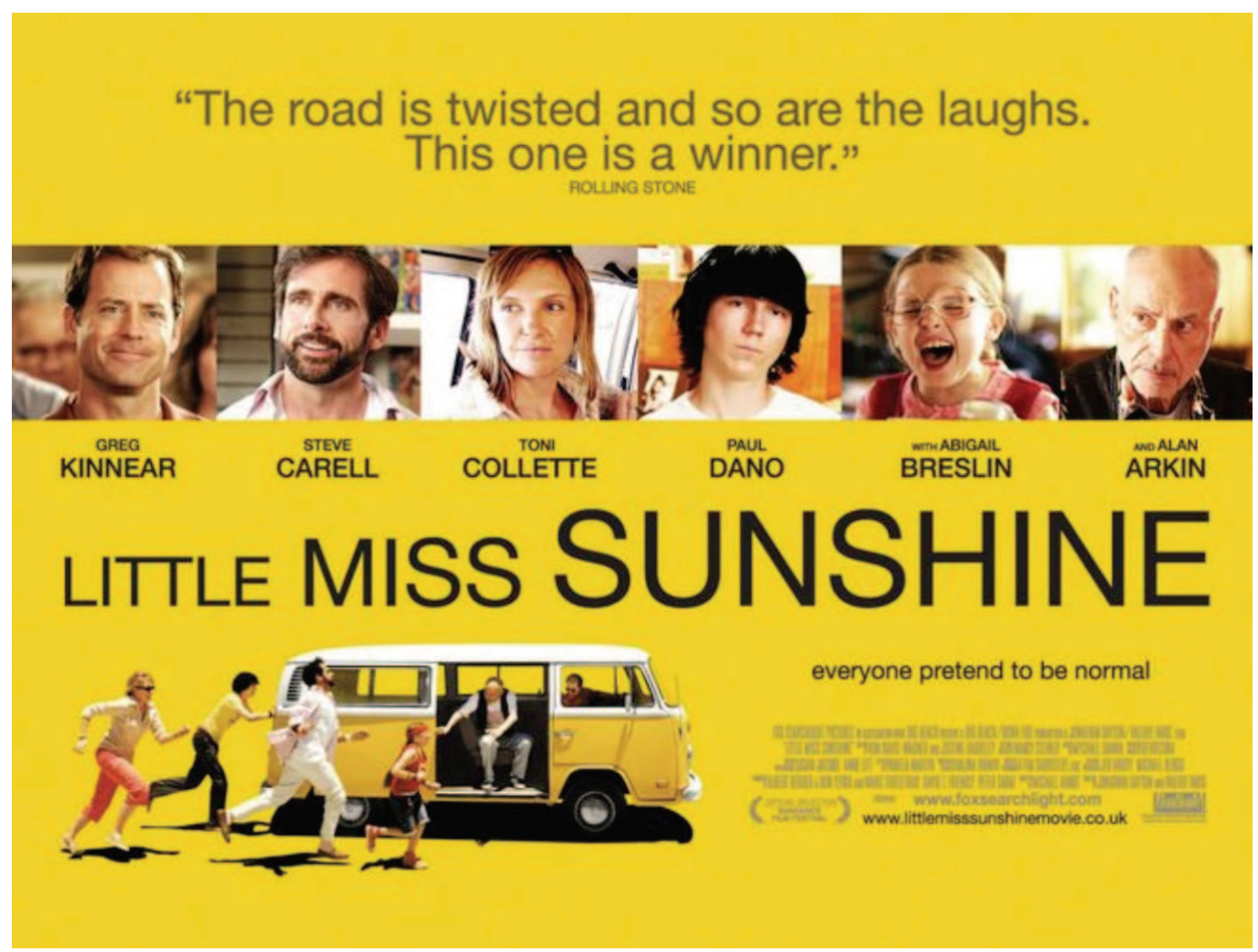

As formas de encaixamento analisadas por meio do exemplo (2) são materializadas na imagem, ao contrário das (supostas) formas de encaixamento realizadas entre uma categoria qualquer da GDV e um atributo simbólico ou um portador (numa estrutura conceitual simbólica), como no exemplo (1), em que o conhecimento a respeito do significado das linhas brancas é subjacente à imagem, ou seja, insere-se num plano de abstração. Em suma, entendemos tratar-se de encaixamento quando há uma representação concreta e simultânea de diferentes categorias numa dada imagem ou entre imagens que compõem um gênero textual, como o anúncio. Como a identificação da estrutura conceitual simbólica requer um conhecimento discursivo, acreditamos ser mais conveniente falar em subjacência, pois o termo nomeia mais adequadamente sua natureza, que é a de representar um posicionamento. Qualquer que seja a categoria (narrativa ou conceitual, etc.), não se pode fugir ao atravessamento ideológico em imagens, que é verificável empiricamente por meio das representações simbólicas. Nesse caso, essa categoria (conceitual simbólica) não pode ser tomada como pertencente ao mesmo patamar das demais. 


\section{SIGNIFICADOS E FUNÇÕES DAS REPRESENTAÇÕES SIMBÓLICAS}

Embora concordemos com os autores a respeito de que em imagens, assim como em textos verbais, constroem-se simultaneamente três significados (ideacional, interpessoal, textual), nem sempre o sentido pretendido pode ser alcançado com a 'soma' da análise dessas três metafunções/estruturas. Muitas vezes, há necessidade de se recorrer, em casos de textos multimodais, a pistas verbais e, em casos de textos estritamente visuais, é preciso buscar inferências a fim de se compreender o sentido expresso pelas imagens, de modo que deve haver uma categoria visual que permita ao espectador realizar inferências a fim de atingir a compreensão da imagem. Defendemos, por isso, que são principalmente os atributos simbólicos e os portadores (categorias da estrutura representacional conceitual simbólica) os responsáveis pelas inferências que fazemos quando da leitura de textos visuais.

No exemplo (3) a seguir, reproduzido de uma capa de revista, só se compreende o tom sarcástico da manchete principal "Fala, Dantas!", quando se associa este enunciado ao atributo simbólico presente na forma de representação da boca do participante representado, que remete às marionetes. A partir desse constituinte, ativa-se uma série de conhecimentos prévios, de modo que se conclui que o participante está sendo manipulado (num primeiro momento, com o sentido de atuar pelas mãos de outro, referente ao conhecimento acerca das marionetes), para em seguida se associar o conceito de manipulação ao controle políticopartidário, e, portanto, o que o participante representado "falar" não será dito efetivamente por ele, mas por quem o manipula. Neste caso, o significado do texto verbal (Fala, Dantas!) e o significado da imagem (homem com boca de marionete) são de certa forma contraditórios, de modo que é o atributo simbólico que proporciona a compreensão da metáfora e da ironia que estão sendo construídas nesse texto multimodal. Resta dizer que o atributo simbólico encontra-se subjacente à representação conceitual analítica que compõe a imagem.

Algo análogo ocorre no exemplo (4), no qual os participantes representados encontram-se estampados em peças de dominó. A leitura dessa imagem à luz da GDV permite identificar um processo acional de 
conversão, em que um ator é a primeira peça do dominó cuja meta é a peça seguinte que, por sua vez, traz estampada outro ator, e assim sucessivamente, numa ação contínua de mudança de estado denominada revezamento, pois há mais peças ao fundo compondo o jogo. Entretanto, não se trata de peças comuns - emolduradas por elas encontram-se fotografias de personalidades políticas -, o que indica que elas devem ser interpretadas como metáforas de peças de dominó, e é o atributo simbólico que permite fazer essa relação. A partir dele compreende-se o "efeito dominó" causado pela série de denúncias e investigações da CPI do Mensalão, que, na época da publicação da revista (15 de junho de 2005), havia chegado a dois nomes apenas, representados visualmente pelas fotos. O texto verbal "Quem mais?" também auxilia na construção da interpretação, embora seja a estrutura visual que possibilita a inferência de que há mais 'peças', ou seja, outras personalidades políticas envolvidas com o escândalo do mensalão.
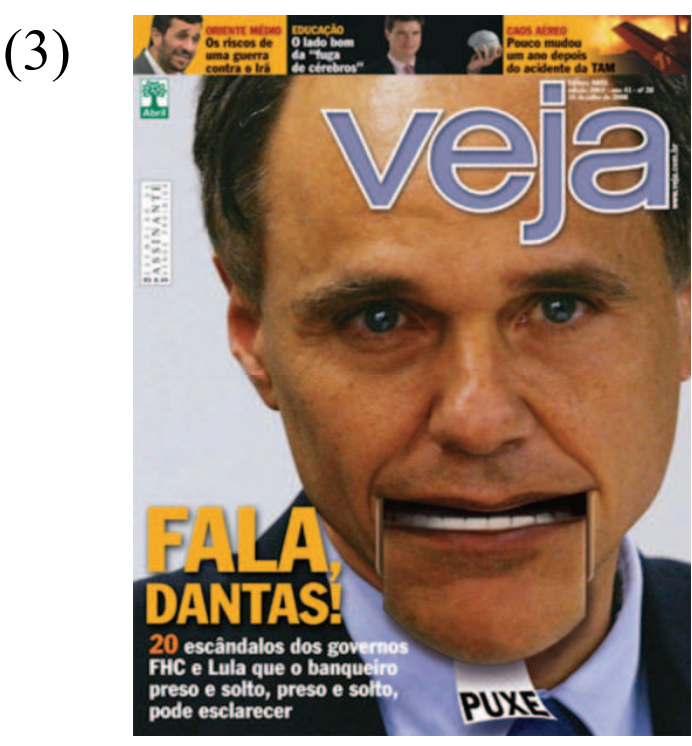

(4)

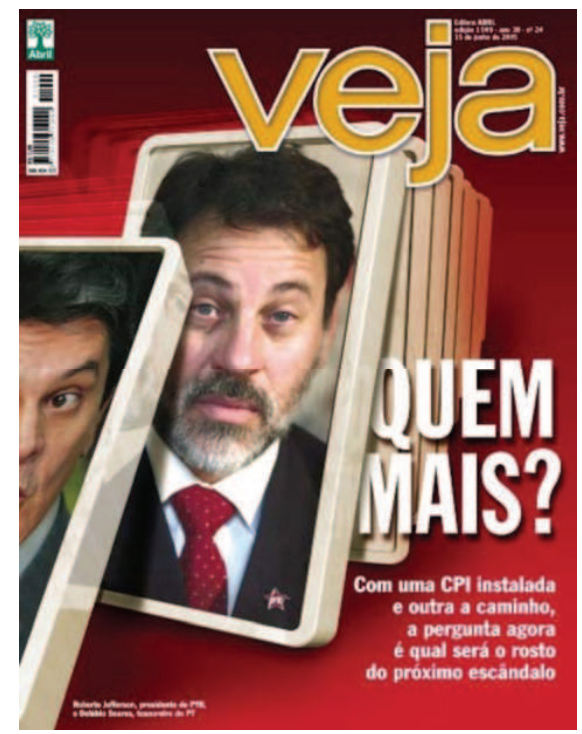

O exemplo (4) permite constatar aquilo que problematizamos: se a metafunção ideacional - assim como as demais - realiza-se através de escolhas de processos, não é possível a sobreposição de duas estruturas ideacionais num mesmo constituinte (um processo narrativo acional e um processo conceitual simbólico). Tampouco se pode afirmar que nos exemplos (3) e (4) há encaixamento de representações, visto que os significados relativos à manipulação de marionetes e ao 'efeito dominó' 
são conhecimentos ideológico-discursivos previamente disseminados em nossa sociedade, ativados pela leitura das imagens.

Afirmar o contrário, isto é, considerar a sobreposição de funções, é uma posição incoerente em relação à teoria de base (a LSF), para a qual a linguagem é um sistema de escolhas, de modo que, quando se seleciona um processo, se excluem os demais. Nesse caso, propomos deslocar os atributos simbólicos - e a própria estrutura conceitual simbólica - a um plano superior, visto que não há imagem cujo significado não seja atravessado por simbologias, logo esse tipo específico de sobreposição seria inevitável.

Alguns analistas críticos do discurso, assim como alguns sistemicistas, colocam a ideologia num plano subjacente às metafunções. Entendemos que, em linguagem visual, as ideologias são perceptíveis justamente na representação dos significados simbólicos, sendo, portanto, inadequado tratá-la num mesmo plano que as demais estruturas, a saber, as narrativas acionais e reacionais, e as conceituais analíticas e classificatórias. Sempre que houver uma representação visual, seja ela narrativa ou conceitual, haverá necessariamente uma representação simbólica subjacente.

O exemplo (5) permite visualizar melhor essa relação entre significados simbólicos (materializados em atributos simbólicos ou portadores) e estruturas narrativas e/ou conceituais. Escolhemos analisálo devido à ausência significativa de textos verbais que, nos exemplos anteriores, auxiliam na construção de significados simbólicos.

Neste anúncio, há nitidamente um processo narrativo de ação transacional em que a sombra (à esquerda) é o ator, a sombra das pernas (na horizontal) é o vetor que une o ator à meta, representada pela moça correndo. Interpreta-se essa imagem como um processo de mudança de um estado de sedentarismo a um estado de plena disposição física, que pode ser garantido pelo consumo de uma barra de cereal cuja imagem se encontra no canto inferior direito do anúncio. Entretanto, só é possível fazer essa interpretação em decorrência da postura da sombra (representando cansaço físico) e da postura da moça (em plena atividade física). Tais posturas são atributos simbólicos dados ao ator e à meta. Sem esses atributos, não seria possível realizarem-se as inferências que permitem compreender o anúncio. 
(5)

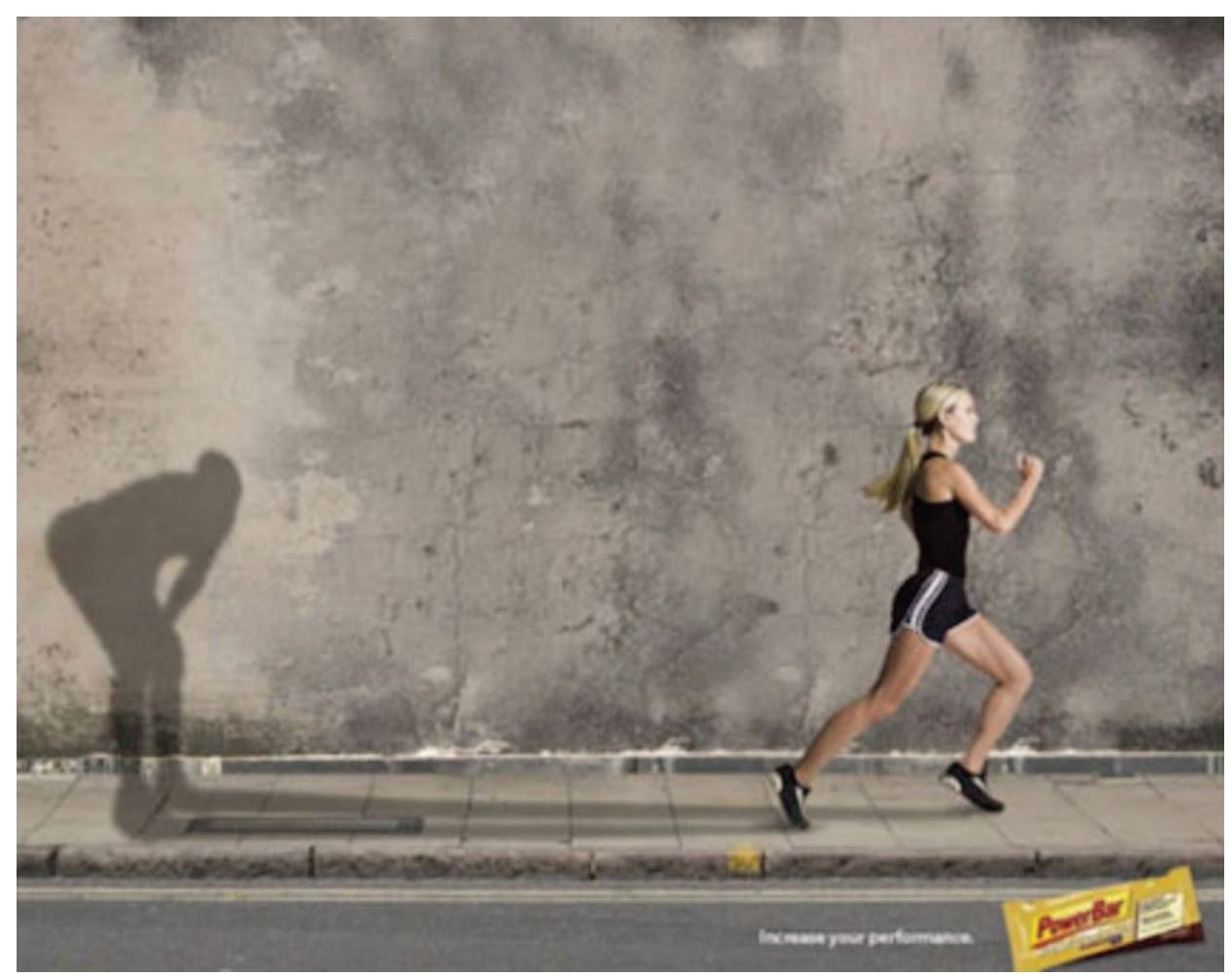

Nesse caso, fica inequívoca a sobreposição de constituintes nos mesmos participantes, algo que, ressaltamos, vai contra os pressupostos da LSF e consequentemente da GDV. Esse fator reforça nossa posição de entender os atributos simbólicos e a própria estrutura conceitual simbólica como intrínsecos a qualquer representação visual, em virtude de não poder haver imagens (ou qualquer outro tipo de texto, seja qual for a semiose que o constitui) desprovidas de uma carga simbólicoideológica.

\section{CONSIDERAÇÕES FINAIS}

Nossas reflexões acerca da Gramática do Design Visual de Kress e van Leeuwen (2006 [1996]) tiveram o intuito de discutir a função dos constituintes denominados atributos simbólicos, que teriam a função de atribuir certos valores a outros constituintes, denominados portadores. Verificou-se, nesse trabalho, que a sua função engloba, mais 
que isso, o estabelecimento de inferências e relações metafóricas que auxiliam na própria compreensão do texto visual.

Além disso, percebemos que há uma sobreposição/simultaneidade de constituintes referentes a um mesmo participante, o que demonstra estarem os atributos simbólicos - e os processos simbólicos conceituais - localizados num plano mais amplo, que envolve os demais. Entendemos que tal sobreposição não consiste num caso de encaixamento, mas sim de subjacência, uma vez que os processos simbólicos apresentam um caráter de signo, portanto indissociáveis de quaisquer representações visuais.

\section{REFERÊNCIAS}

BARTHES, R. Elementos de semiologia. 10 ed. São Paulo: Cultrix, 1997.

BAKHTIN, M. O problema do texto. In: Estética da criação verbal. Tradução feita a partir do francês por Maria Ermantina Galvão. Revisão de tradução: Maria Appenzeller. 3ed. São Paulo, Martins Fontes, 2000 [1959-1961].

BAKHTIN, M./VOLOSHINOV, V. N. Marxismo e filosofia da linguagem. Trad. Michel Lahud e Yara Frateschi Vieira. 10 ed. São Paulo: Hucitec, 2002 [1929].

HALLIDAY, M.A.K. An introduction to functional Grammar. 2ed. London: Edward Arnold, 1994 [1985].

KERBRAT-ORECCIONI, C. Análise da conversação: princípios e métodos. Trad. Carlos Piovezani Filho. São Paulo: Parábola editorial, 2006 [1996].

KNOLL, G. F. Relações de gênero na publicidade: palavras e imagens constituindo identidades. Dissertação/mestrado em Linguística. Programa de Pós-Graduação em Letras. Universidade Federal de Santa Maria (UFSM-RS). $136 \mathrm{p}$.

KOCH, I. G. V. Princípios teórico-analíticos da Linguística Textual. In: As tramas do texto. Rio de Janeiro: Nova Fronteira, 2008. p. 11-25.

KRESS, G.; VAN LEEUWEN, T. Multimodal discourse: the modes and media of contemporary communication. London: Oxford University Press, 2001. 
KRESS, G.; VAN LEEUWEN, T. Reading images: the grammar of visual design. 2ed. London: Routledge, 2006 [1996].

PINHEIRO, V. S; MAGALHÃES, C. A representação de atores sociais em capas da revista "Raça Brasil". In: Procedings of the 33rd International Systemic Funtional Congress. 2006. p. 489-513.

SAUSSURE, F. de. Curso de linguística geral. $7^{\mathrm{a}}$ ed. São Paulo: Cultrix, 1975 [1916].

Recebido em 04/09/09. Aprovado em 23/03/10.

Title: On the functions of symbolic conceptual representations in the grammar of visual design: embedded or underlying patterns?

Abstract: Our aim in this article is to discuss the function of the grammatical categories symbolic attribute and carrier in the Grammar of Visual Design (Kress and van Leeuwen, 2006 [1996]). For the authors, these constituents, belonging to the ideational metafunction, could be present or not in symbolic conceptual structures, giving a participant a value that would characterize and/or conceptualize him. We advocate that, as a result of the ideational function, symbolic attributes and carriers are responsible for the production of inferences by the readers of images and, therefore, are always present in any visual representation. As a result, we believe that symbolic conceptual representations are not at the same level of autonomy as classifying and analytical narrative and conceptual representations, but at the level of underlying patterns.

Keywords: multimodality; visual texts; representational structures; symbolic attributes. 